\title{
Analysis of Genomes Changes in Pseudomonas Chlororaphis Subsp. Aurantiaca Strains Producing Phenazines
}

Anastasia I. Liaudanskaya ( $\sim$ tassigo@gmail.com )

BSU: Belorusskij gosudarstvennyj universitet https://orcid.org/0000-0002-3735-537X

Natalia P. Maximova

BSU: Belorusskij gosudarstvennyj universitet

Katsiaryna G. Verameyenka

BSU: Belorusskij gosudarstvennyj universitet

\section{Research Article}

Keywords: Pseudomonas bacteria, aromatic pathway, phenazines, mutagenesis, genome assembly

Posted Date: March 16th, 2021

DOI: https://doi.org/10.21203/rs.3.rs-289228/v1

License: (c) (i) This work is licensed under a Creative Commons Attribution 4.0 International License.

Read Full License 


\section{Abstract}

Genomes of three strains - phenazine producers - Pseudomonas chlororaphis subsp. aurantiaca (B-162 (wild-type), mutant strain B-162/255 and its derivatives B-162/17) were sequenced and compared. All genome annotations revealed 6347 CDS, 5 rRNA clusters (5S, 16S, 23S) and 59 tRNA genes. Comparison analysis of wild-type strain and B-162/255 mutant strain genomes allowed revealing 32 mutations. 19 new mutations were detected upon comparison of genomes strains B-162/255 and B-162/17. Further bioinformatics analysis allowed predicting mutant proteins' functions and secondary structures of five gene products, mutations in which might potentially have influence on phenazine synthesis and secretion in Pseudomonas bacteria. These genes are phenylalanine hydroxylase transcriptional activator PhhR, type I secretion system ATPase, transcriptional regulator MvaT, GacA response regulator and histidine kinase. Amino acid substitutions were located in domain structures of corresponding proteins.

\section{Introduction}

Rhizospheric plant-growth-promoting bacteria Pseudomonas produce a broad spectrum of biologically active metabolites. One of the most interesting secondary metabolites synthesized by Pseudomonas are phenazines - a large group of nitrogen-containing heterocyclic compounds that differ in chemical and physical properties. Diversity of these characteristics makes phenazines wide-spreaded in nature and facilitates their application in industry, agriculture and medicine [1,3]. Phenazines ability of conversion soil minerals to bioaccessible forms upgrades plant mineral nutrition and stimulates their growth. Moreover, involvement of phenazines in microbial biofilm formation protects plant roots against soil phytopathogens due to high concentration of different antimicrobial substances. Due to similarity of phenazine structure to flavin cofactors they take an active role in the electron transport and display high redox potential. It allows using phenazines as mediators which enhance electrons transfer from redox enzymes to the electrodes. This property is useful for biosensor construction, hence phenazines may be engaged in design of luminescent and amperometric sensors [4, 5]. Biofuel elements were constructed using immobilized phenazine producer-cells fixed on anode. Moreover it is possible to increase properties of Escherichia coli as the microbial fuel cells introducing phz-operon into genome [8, 9]. In addition to antibacterial and antifungal activities phenazines can be used in medicine for treatment of helminthiasis, malaria and even cancer $[10,11]$.

Phenazines generally are synthesized intracellularly and then secreted into the surrounding environment $[1,2]$. Phz-operon containing seven genes (phzABCDEFG) was identified in many Pseudomonas. Products of these genes control reactions of metabolic pathway leading to phenazines synthesis $[2,6]$ Furthermore, deletion of these genes in Pseudomonas aeruginosa PAO1 induced changes in other bacterial genes expression. It was also found that pyocyanin (one of phenazines) supplied into the cultural medium acted as a gene expression regulator for 51 genes in $P$. aeruginosa PAO1 [7]. Similar experiments in Pseudomonas chlororaphis demonstrated phenazines` effect on genes encoding proteins associated with cell adhesion and biofilm formation [2]. 
Nevertheless, creation of highly active producers of phenazines by genetic engineering methods remains problematic. One of the reasons hindering large-scale manufacturing of these metabolites is a limited set of expression vectors suitable for Pseudomonas bacteria. Phenazine production by E. coli strains is also difficult due to complex organization of phenazine metabolic pathways that are not limited to the control by phz-operon products. According to [9] transformation the phz-gene cluster into E. coli BL21(DE3) showed very low level of phenazine production in recombinant strain. Therefore, the most effective approach nowadays is the chemical mutagenesis and subsequent selection on superproduction.

Pseudomonas chlororaphis subsp. aurantiaca B-162 was obtained from the collection of microorganisms of Genetics Department of the Belarusian State University. This strain demonstrated stable phenazine production. Initial phenazine production level in this strain on the production media [14] was $75 \pm 15 \mathrm{mg} / \mathrm{l}$. This wild-type strain was further used for the mutagenesis and selection of highly productive strains-producers (Fig. 1.) [12, 13]. Two mutant strains-producers B-162/255 and B-162/17 were derived following sequential mutagenesis coupled with the selection on resistance to toxic analog of aromatic amino acid (Fig. 1).

Phenazine synthesis level in B-162/255 strain on production media was about $420 \pm 30 \mathrm{mg} / \mathrm{l}$ and B$162 / 17$ derived from B-162/255-210 $\pm 25 \mathrm{mg} / \mathrm{l}$ (Fig. 1). A prominent feature of the last mutant was the ability to synthesize phenazine antibiotics on minimal media [15] at the same level as on production media. It is worth emphasizing that the B-162 strain and the mutant strain B-162/255 do not synthesize phenazines on minimal media at all. To our knowledge, such strain was obtained for the first time.

The main disadvantage of chemical mutagenesis is the difficulty in the identification of the exact mutation sites and consequently - the genes that potentially could have influence on studied process. The modern NGS-sequencing technologies solve most of arising problems.

The main purpose of this study was to identify the differences between the genomes of wild-type and mutant strains bacteria $P$. chlororaphis subsp. aurantiaca, capable of phenazines producing. Comparative analysis of sequenced, assembled and annotated genomes revealed mutations in strains-producers genes that potentially could be essential for phenazines synthesis.

\section{Materials And Methods}

Mutant strains $P$. chlororaphis subsp. aurantiaca B-162/255 and $P$. chlororaphis subsp. aurantiaca B$162 / 17$ were created by series of chemical mutagenesis coupled with the appropriate selection $[12,13]$. All bacterial strains (wild-type and mutant) were cultivated on agar plates at $28{ }^{\circ} \mathrm{C}$.

Genomic bacterial DNA was extracted using GeneJET Genomic DNA Purification Kit K0881 (Thermo Scientific). Nextera XT DNA Library Preparation Kit (Illumina) was used to prepare samples for sequencing. Whole genome was sequenced with MiSeq Reagent Kit v2 on Illumina MiSeq at the Institute of Genetics and Cytology, National Academy of Sciences of Belarus. 
Raw reads from the Illumina MiSeq data were trimmed to remove adapters and low-quality nucleotide stretches with Trimmomatic 0.38 . Genome assembly was conducted using software SPAdes 3.13 .1 and A5-miseq (v2016-08-25). Genome annotation was performed with RAST (http://rast.nmpdr.org/) and NCBI Prokaryotic Genome Annotation Pipeline (PGAP). The resulting genome sequences were aligned with Clustral Omega tool (https://www.ebi.ac.uk/Tools/msa/clustalo/). Motif analysis was carried out with the MEME Suit (http://meme-suite.org/tools/meme).

There were used sequences of $P$. chlororaphis subsp. aurantiaca DSM 19603 (accession number CP027746), P. chlororaphis subsp. aurantiaca B-162 (accession number CP050510.1).

\section{Results And Discussion}

\subsection{Genome assembly}

For $P$. chlororaphis subsp. aurantiaca B-162 initially 478 contigs were assembled with SPAdes and 318 contigs with A5-misEq. The comparison of these contigs with the sequences from NCBI GenBank database showed the highest identity with the whole genome sequence of $P$. chlororaphis subsp. aurantiaca DSM 19603 (accession number CP027746). Contigs were aligned on this genome to filter them. After that only 26 from SPAdes assembly and 50 contigs from A5-miseq assembly were sorted out to make the final version of $P$. chlororaphis subsp. aurantiaca B-162 genome sequence. The assembled sequence dimension was $7109866 \mathrm{bp}$. This genome size corresponds to the size of $P$. chlororaphis subsp. aurantiaca complete chromosome nucleotide sequences deposited into GenBank database. No extra chromosomal elements were found. GC-content for this sequence was $62.7 \%$. Genome annotation revealed 6347 CDS, 5 rRNA clusters (5S, 16S, 23S) and 59 tRNA genes. The $P$. chlororaphis subsp. aurantiaca B-162 genome sequence was submitted to GeneBank (accession number CP050510.1) [16].

For P. chlororaphis subsp. aurantiaca B-162/255 initially 452 contigs were assembled with SPAdes and 218 contigs with A5-misEq. Contigs were filtered as in previous case. After that only 32 contigs from SPAdes assembly and 28 contigs from A5-miseq assembly were applied to make the final version of $P$. chlororaphis subsp. aurantiaca B-162/255 genome sequence. The assembled sequence was the same length as the wild-type assembled genome. Extra chromosomal elements also were not found. GCcontent for this sequence was $62.5 \%$. Genome annotation revealed 6347 CDS, 5 rRNA clusters (5S, 16S, 23S) and 59 tRNA genes similar to P. chlororaphis subsp. aurantiaca B-162 genome.

For $P$. chlororaphis subsp. aurantiaca B-162/17 initially 502 contigs were assembled with SPAdes and 281 contigs with A5-misEq. After the alignment of these contigs on the reference genome only 26 contigs from SPAdes assembly and 29 contigs from A5-miseq assembly were applied to make the final version of P. chlororaphis subsp. aurantiaca B-162/17 genome sequence. The assembled sequence included 7109 $813 \mathrm{bp}$ length that is $53 \mathrm{bp}$ lower than in both previous genomes. Despite this, genome annotation also revealed 6347 CDS, 5 rRNA clusters (5S, 16S, 23S), 59 tRNA genes and no extra chromosomal elements. 


\subsection{Comparative analysis $P$. chlororaphis subsp. aurantiaca genomes}

\subsubsection{Comparison of $P$. chlororaphis subsp. aurantiaca B- 162 and $P$. chlororaphis subsp. aurantiaca B-162/255 genomes}

To make a prediction about mutations that could cause phenazine production changes it is important to identify specific SNPs and functions of products of corresponding genes. The obtained sequences of B162 and B-162/255 strains were aligned and 32 mutations were identified. All of them were qualified as single nucleotide polymorphisms (SNP). Six of these SNPs located in intergenic regions could hardly affect Pseudomonas metabolism. Among the rest 26 SNPs, 8 SNPs failed to modify amino acids and 3 induced conserved replacements (Table 1). Thus it was decided to focus on the remaining 15 genes with potentially important SNPS.

It is known that $16 \mathrm{~S}$ ribosomal RNA (16S rRNA) is the component of the $30 \mathrm{~S}$ small subunit of prokaryotic ribosome that binds to the Shine-Dalgarno sequence during translation [17]. The mutation that caused change proline to serine at position 108 was not important. This amino acid located at the initial part of a-helix and hadn`t an influence on binding or active

Table 1

List of proteins that are encoded by genes with detected mutations in comparative analysis of $P$. chlororaphis subsp. aurantiaca B-162 and $P$. chlororaphis subsp. aurantiaca B-162/255 strains 


\begin{tabular}{|c|c|c|}
\hline Name of protein & $\begin{array}{l}\text { Position of mutation } \\
\text { in genome, bp }\end{array}$ & $\begin{array}{l}\text { Kind of } \\
\text { mutation }\end{array}$ \\
\hline 16s rRNA & 29758 & $\begin{array}{l}\text { G->A (Pro- } \\
>\text { Ser) }\end{array}$ \\
\hline MerR family DNA-binding transcriptional regulator & 823359 & $\begin{array}{l}\text { G->A }(\text { Thr- } \\
>\text { Ile) }\end{array}$ \\
\hline Hypothetical protein & 1005953 & $\begin{array}{l}\text { C->G (Ser- } \\
>\text { Ser })\end{array}$ \\
\hline Rod shape-determining protein MreC & 1028732 & $\begin{array}{l}\text { T->C (Ser- } \\
>\text { Pro) }\end{array}$ \\
\hline $\begin{array}{l}\text { BioD-like N-terminal domain / Phosphate acetyltransferase } \\
\text { (EC 2.3.1.8) }\end{array}$ & 1066431 & $\begin{array}{l}\mathrm{G}->\mathrm{A}(\mathrm{Val}- \\
>\mathrm{Val})\end{array}$ \\
\hline Translation elongation factor LepA & 1193213 & $\begin{array}{l}\mathrm{G}->\mathrm{A}(\mathrm{Val}- \\
>\mathrm{Ile})\end{array}$ \\
\hline Prophage tail fiber protein & 1380270 & $\begin{array}{l}\text { G->A (Val- } \\
>\text { Ile) }\end{array}$ \\
\hline 3-carboxy-cis,cis-muconate cycloisomerase (EC 5.5.1.2) & 1476654 & $\begin{array}{l}\text { G->A (Gly- } \\
>\text { Asp) }\end{array}$ \\
\hline $\begin{array}{l}\text { Cytosine/purine/uracil/thiamine/allantoin permease family } \\
\text { protein }\end{array}$ & 1697326 & $\begin{array}{l}\text { G->A (Arg- } \\
>\text { Arg) }\end{array}$ \\
\hline Phenylalanine hydroxylase transcriptional activator PhhR & 1758287 & $\begin{array}{l}\text { G->A (Met- } \\
>\text { Ile) }\end{array}$ \\
\hline ADP-ribosylglycohydrolase & 1985343 & $\begin{array}{l}\text { G->A (Pro- } \\
>\text { Pro) }\end{array}$ \\
\hline Sigma-54-dependent transcriptional regulator & 2820154 & $\begin{array}{l}\text { G->A (Gly- } \\
>\text { Asp) }\end{array}$ \\
\hline Hypothetical protein & 2864629 & $\begin{array}{l}\text { G->A (Arg- } \\
>\text { Arg) }\end{array}$ \\
\hline $\begin{array}{l}\text { Domain of unknown function / Regulator of nucleoside } \\
\text { diphosphate kinase }\end{array}$ & 3387091 & $\begin{array}{l}\text { G->A (Asn } \\
\rightarrow \text { Asn) }\end{array}$ \\
\hline $\begin{array}{l}\text { Type I secretion system ATPase, ABC-type protease exporter, } \\
\text { ATP-binding component PrtD/AprD }\end{array}$ & 3633870 & $\begin{array}{l}\text { C->G (Gly - } \\
>\text { Arg) }\end{array}$ \\
\hline Transcriptional regulator MvaT, P16 subunit, putative & 3794621 & $\begin{array}{l}\text { G->A (Gly - } \\
>\text { Asp) }\end{array}$ \\
\hline Isoquinoline 1-oxidoreductase beta subunit (EC 1.3.99.16) & 4327280 & $\begin{array}{l}\text { G->A (Val - } \\
>\text { Met) }\end{array}$ \\
\hline BarA-associated response regulator UvrY $(=\mathrm{GacA}=\mathrm{Sir} A)$ & 4440666 & $\begin{array}{l}\text { G->T }(\text { Ser - } \\
>\text { Arg) }\end{array}$ \\
\hline
\end{tabular}




\begin{tabular}{|lll|}
\hline Name of protein & $\begin{array}{c}\text { Position of mutation } \\
\text { in genome, bp }\end{array}$ & $\begin{array}{c}\text { Kind of } \\
\text { mutation }\end{array}$ \\
\hline $\begin{array}{l}\text { Transcriptional regulator (Sigma-54 dependent transcriptional } \\
\text { regulator) }\end{array}$ & 4452736 & $\begin{array}{c}\text { G->T (Glu - } \\
\text { > Lys) }\end{array}$ \\
\hline Uncharacterized MFS-type transporter & 4775194 & $\begin{array}{l}\text { G->A (Phe } \\
\text {-> Phe) }\end{array}$ \\
\hline Hypothetical protein & 4778132 & $\begin{array}{l}\text { G->A (Val - } \\
\text { > Met) }\end{array}$ \\
\hline DNA-directed RNA polymerase alpha subunit (EC 2.7.7.6) & 6398527 & $\begin{array}{l}\text { T->A (Asn - } \\
>\text { Ile) }\end{array}$ \\
\hline Predicted signal transduction protein (histidine kinase) & 6714169 & $\begin{array}{l}\text { G->A (Thr - } \\
>\text { Ile) }\end{array}$ \\
\hline $\begin{array}{l}\text { Alginate regulatory protein AlgP, positive transcriptional } \\
\text { regulator of AlgD }\end{array}$ & 6843467 & $\begin{array}{l}\text { C->T (Ala - } \\
>\text { Ala) }\end{array}$ \\
\hline Uncharacterized protein (Thioredoxin) & 6876184 & $\begin{array}{l}\text { G->A (Leu } \\
\text {-> Phe) }\end{array}$ \\
\hline DNA-binding protein with helix-turn-helix motif & 6971830 & $\begin{array}{l}\text { G->A (Pro - } \\
\text { > Ser) }\end{array}$ \\
\hline Note: Grey-colored genes carry mutations which may potentially affect protein functions. & \\
\hline
\end{tabular}

sites of this protein. Locations of these sites were determined with the aid of homologous sequence (accession number in UniProt Q88RR3).

According to Brown, N.L. et al. the MerR family is a group of transcriptional activators with similar Nterminal helix-turn-helix DNA binding regions and C-terminal effector binding regions that are specific to the effector recognition. The few MerR-like regulators studied experimentally have been shown to activate suboptimal $\sigma^{70}$-dependent promoters. The majority of regulators of this family respond to environmental stimuli, such as oxidative stress, heavy metals or antibiotics. A subgroup of the family activates transcription in response to metal ions [18]. The mutation that caused threonine to isoleucine replacement at position 51 occurred in helix-turn-helix domain according to homologous sequence (accession number in UniProt A0A37915Y4) and could influence activity of this protein.

It is known that rod shape-determining protein $\mathrm{MreC}$ is responsible for cell-morphology and several antibiotics sensitivity [19]. According to homologous sequence (accession number in UniProt W6QQZ2) the mutation that altered serine to proline at position 40 could not change active site of this protein.

3-carboxy-cis,cis-muconate cycloisomerase is the enzyme that catalyzes the conversion reaction of 2carboxy-2,5-dihydro-5-oxofuran-2-acetate to cis,cis-butadiene-1,2,4-tricarboxylate [20]. The mutation that caused substitution glycine to aspartic acid at position 255 occurred in a-helix region and could not affect active sites of the protein according to homologous sequence (accession number in UniProt Q916Q8). 
PhhR is transcriptional regulator that induces a cluster of structural genes phhABC encoding phenylalanine hydroxylase, carbinolamine dehydratase and aromatic aminotransferase respectively [21, 22]. Thus, PhhR is a global regulator responsible for the activation of genes essential for phenylalanine degradation and phenylalanine homeostasis. The mutation that replaced methionine with isoleucine at position 260 occurred in $\sigma^{54}$-factor interaction domain of this protein according to homologous sequence (accession number in UniProt G8PZM7). Motif analysis of these sequences showed the location of the mutation inside of motif sequence (Fig. 2). Since it is known that 3-deoxy-D-arabino-heptulosonate-7phosphate (DAHP) synthase is regulated by phenylalanine and DAHP synthase is the key enzyme of shikimic acid pathway that leads to phenazines production [23] it seems that SNP in this gene could probably cause changes in phenazine antibiotics biosynthesis by mutant strain B-162/255.

It is known that transcription by RNA-polymerase utilizing $\sigma 54$-factor is regulated by a distinct class of positive activators $-\sigma^{54}$-dependent family regulators. The activities of these regulators are modulated in response to a wide variety of environmental signals. Factors that modulate the expression or the activity of the regulatory protein in response to chemical and metabolic changes are ultimately responsible for determining the level of expression of $\sigma^{54}$-dependent genes and hence the diverse bacterial functions which they encode [24]. According to homologous sequence (accession number in UniProt Q880V5) the mutation that provokes glycine to aspartic acid replacement at position 268 is far away from interaction site of this protein and can't interfere with its regulatory aspects.

Type I secretion systems consist of three membrane-localized proteins: $A B C$ transporter, a membrane fusion protein and a TolC-like outer membrane component [25]. Using these systems a variety of small molecules such as antibiotics and toxins are removed from cells of gram-negative bacteria [26]. The mutation at position 357 took place in $A B C$ transporter domain of B-162/255 strain according to homologous sequence (accession number in UniProt G8Q331). Motif analysis also showed the location of the mutation inside of motif sequence (Fig. 3).

Transcriptional regulator MvaT is a negative controller of chaperone-usher pathway gene cluster responsible for the biofilm formation in Pseudomonas bacteria [27]. According to the literature [28] biofilm formation may influence on phenazine synthesis in bacteria of this genus. Well known that this transcriptional regulator governs type III secretion system by repressing gene expression [29]. The mutation that replaced glycine with aspartic acid at position 98 did not exert any effect on regulatory sites of this protein according to homologous sequence (accession number in UniProt Q4KB87).Nevertheless motif analysis showed the location of the mutation in the center of motif sequence (Fig. 4). 
Isoquinoline 1-oxidoreductase catalyzes the hydroxylation of isoquinoline to 1-oxo-1,2dihydroisoquinoline with subsequent reduction of a suitable electron acceptor utilizing $\mathrm{H}_{2} \mathrm{O}$ as the source of oxygen atom incorporated into the substrate [30]. The discovered mutation converting valine to methionine at position 581 probably cannot produce any impact on binding or active sites of this protein. Location of these sites was established with help of homologous sequence (accession number in UniProt A0A098T303).

We also determined mutation in GacA-response regulator gene. In Pseudomonas spp. secondary metabolism is controlled by the GacS/GacA global regulatory system. It determines the production of metabolites with antimicrobial activity including phenazines [31]. The mutation resulting in serine to arginine substitution at position 107 occurred between regulatory domains. Locations of these domains were evaluated via mediation of homologous sequence (accession number in UniProt P32967). Motif analysis of these sequences showed the location of the mutation inside of motif sequence (Fig. 5). It seems that this SNP could cause phenazine antibiotics biosynthesis by mutant strain B-162/255.

Another SNP was found in the gene encoding sigma factor $\sigma^{54}$-dependent transcriptional regulator. The alteration of glutamic acid to arginine at position 420 was not localized in the interaction site of this protein and can't influence its regulatory features.

It is widely known that DNA-directed RNA-polymerase is the enzyme that involved in transcription [17]. The mutation inducting asparagine to isoleucine change at position 273 occurred in a-C-terminal domain, but this amino acid was not involved in formation any active sites of protein. Location of this domain was specified using the homologous sequence of RNA-polymerase (accession number in UniProt Q4K557).

Histidine kinases are multifunctional, transmembrane proteins plays a key role in signal transduction across the cellular membrane [32]. Moreover, some of them are engaged in bacterial biofilm formation. Biofilms are bacterial microcolonies that may surround the roots of plants and protect them from pathogenic fungi thanks to produced phenazines [1]. The mutation causing threonine to isoleucine change at position 178 took place in regulatory domain according to homologous sequence (accession number of reference sequence in UniProt A0A0X1SW14). Motif analysis of these sequences showed the location of the mutation inside of motif sequence (Fig. 6). Therefore, this mutation potentially could promote phenazine production in B-162/255 mutant strain.

Thioredoxins are small redox-active proteins discovered in all organisms [33]. They play an essential role in important biological processes, including redox signaling. Mutation that caused leucine to phenylalanine change at position 301 by-passed the signal region was found in B-162/255 strain. 
Location of this region was determined with the help of homologous sequence (accession number in UniProt A0A089YX54).

The last protein was annotated as DNA-binding protein with helix-turn-helix motif. These proteins usually have a regulatory function [17]. The discovered mutation caused change of proline to serine at position 63 and took place in regulatory domain. Location of this domain was determined based on homologous sequence (accession number in UniProt Q4K3L3).

\subsubsection{Comparison of $P$. chlororaphis subsp. aurantiaca B- $162 / 255$ and $P$. chlororaphis subsp. aurantiaca B-162/17 genomes}

On the next step of the research sequences of B-162/255 and B-162/17 strains were compared. As it was mentioned above phenazines production in strain B-162/17 is higher than in wild-type bacteria but lower than in strain B-162/255. However, its distinctive feature is a production of phenazines on minimal media. To understand reasons of initiating phenazine production on minimal media sequences of B162/255 and B-162/17 strains were aligned and 19 mutations were found. 16 of them were qualified as single nucleotide polymorphisms (SNP). Two of these SNPs located in intergenic regions hardly could affect phenazines metabolism. Among the rest 14 SNPs revealed in annotated gene sequences, 5 SNPs failed to modify amino acids and 3 induced conserved replacements (Table 2). Thus it was decided to focus on remaining 5 genes with potentially important SNPs. In addition to SNPs 3 deletions and 2 insertions were also detected. Two of these deletions directly influenced genes sequences so that they were included in the future analysis. The rest deletions and insertions happened in the intergenic regions.

As well as in the previous case to make a prediction about mutations that could cause phenazine production changes we analyzed all genes with potentially important SNPs.

Mutations that can be seen in genes that encode phenylalanine hydroxylase transcriptional activator PhhR and type I secretion system ATPase, ABC-type protease exporter, ATP-binding component PrtD/AprD are reverse mutations and sequence of these genes in B-162/17 strain was the same as in wild-type B162 strain. Given the likely contribution of these genes in phenazine biosynthesis regulation and transport, it can be assumed that these reverse mutations could influence on phenazine production reduction in B-162/17 comparing to B-162/255 in special production media. The rest mutations appeared in $\mathrm{B}-162 / 17$ de novo.

Table 2

List of proteins that are encoded by genes with detected mutations in comparative analysis of $P$. chlororaphis subsp. aurantiaca B-162/255 and $P$. chlororaphis subsp. aurantiaca B-162/17 strains 


\begin{tabular}{|c|c|c|}
\hline Name of protein & $\begin{array}{l}\text { Position of } \\
\text { mutation } \\
\text { in genome, } \\
\text { bp }\end{array}$ & Kind of mutation \\
\hline Cytochrome c oxidase polypeptide I (EC 1.9.3.1) & $\begin{array}{l}68730- \\
68741\end{array}$ & $\begin{array}{l}\text { Deletion of } \\
\text { ccatgatgctga-region }\end{array}$ \\
\hline \multirow{2}{*}{$\begin{array}{l}\text { Hypothetical protein (Outer membrane autotransporter barrel } \\
\text { domain) }\end{array}$} & 1649557 & C->T (Asp->Asn) \\
\hline & 1649565 & T->A (Gln-> Leu) \\
\hline Phenylalanine hydroxylase transcriptional activator PhhR & 1758287 & $A->G(l l e->M e t)$ \\
\hline RND efflux system, inner membrane transporter KPN_02144 & 2468524 & T->G (Val-> Gly) \\
\hline Immune-responsive protein 1 & 3276536 & G->A (Leu-> Leu) \\
\hline $\begin{array}{l}\text { Type I secretion system ATPase, ABC-type protease exporter, } \\
\text { ATP-binding component PrtD/AprD }\end{array}$ & 3633870 & G->C (Arg ->Gly) \\
\hline Hypothetical protein & 5018979 & T $>$ C (Leu $>$ Pro $)$ \\
\hline Efflux ABC transporter, permease/ATP-binding protein & 5203838 & G->A (Ala $>>$ Val) \\
\hline Hypothetical protein & 5319599 & G->A (Val -> Val) \\
\hline Arginine N-succinyltransferase, alpha subunit (EC 2.3.1.109) & $\begin{array}{l}5392805- \\
5392824\end{array}$ & $\begin{array}{l}\text { Deletion of } \\
\text { ttcgccgacgcccagggctt- } \\
\text { region }\end{array}$ \\
\hline Glutaredoxin-related protein & 5679384 & G->A (Thr $->$ Thr) \\
\hline $\begin{array}{l}\text { PTS system, glucose-specific IIA component (EC 2.7.1.199) / } \\
\text { Phosphotransferase system, phosphocarrier protein HPr / } \\
\text { Phosphoenolpyruvate-protein phosphotransferase of PTS } \\
\text { system (EC 2.7.3.9) }\end{array}$ & 5753338 & G->T (Leu -> Met) \\
\hline Hypothetical protein & 5832784 & G->A (Asp-> Asp) \\
\hline $\begin{array}{l}\text { Alginate regulatory protein AlgP, positive transcriptional } \\
\text { regulator of AlgD }\end{array}$ & 6843467 & C $->$ T (Ala $\rightarrow$ Ala $)$ \\
\hline
\end{tabular}

Cytochrome $c$ oxidase catalyzes electron transfer and proton translocation reactions across membranes [34]. This enzyme consists of several subunits. The mutation in B-162/17 strain that caused deletion of 12 nucleotides led to the loss of 4 amino acids without a frameshift. One of the a-helix was reduced but it did not influence the formation of metal-binding site positioned 10 amino acids to the right of the deleted region according to homologous sequence (accession number in UniProt Q91426).

Outer membrane autotransporter barrel-domain is a structural domain found in some bacterial outer membrane proteins [35]. The domain always located at the C-terminal end of the protein forms a $\beta$-barrel structure. The barrel is oriented in the membrane so that the $\mathrm{N}$-terminal end of the protein, termed the 
passenger domain, presents on the cell surface. Two SNPs were detected in this sequence but none of them can influence on binding or active sites of the protein according to homologous sequence (accession number in UniProt A0A370LAR4).

According to comprehensive enzyme information system BRENDA [36] arginine N-succinyltransferase is an enzyme that catalyzes the chemical reaction of condensation of succinyl-CoA and L-arginine. The mutation that caused deletion of 20 nucleotides led to the frameshift and massive sequence changes on the $\mathrm{C}$-terminus. There is no data about regulatory sites locations on this terminus. However, according to homologous sequence (accession number in UniProt P80357) formation of $\beta$-strand is disturbed by the frame shift. Potentially, it could alter the activity and (or) substrate specificity.

Cabeen, M.T. et al. discovered that phosphotransferase system is a major mechanism used by bacteria for carbohydrates recognition and uptake. Gene ptsP encodes enzyme I of the nitrogen-regulated phosphotransferase system vital for cyclic-di-GMP production and for biofilm formation [37]. The mutation site that initiated glycine to aspartic acid change at position 843 is far from any regulatory domains of this protein according to homologous sequence (accession number of reference sequence in UniProt Q4K6X2); therefore, its influence on protein function is minor.

\section{Conclusion}

The chemical mutagenesis of $P$. chlororaphis subsp. aurantiaca B-162 bacteria caused spontaneous genome mutations and resulted in modified bacterial strains $P$. chlororaphis subsp. aurantiaca B-162/255 and $P$. chlororaphis subsp. aurantiaca B-162/17 capable of synthesizing phenazines more efficiently than wild-type culture.

Comparative analysis of wild-type strain and $P$. chlororaphis subsp. aurantiaca

B-162/255 genomes allowed revealing 32 mutations, 16 of which potentially might affect the increase of phenazines production. The most likely candidates for super production provision are mutations in genes encoding phenylalanine hydroxylase transcriptional activator PhhR, type I secretion system ATPase, transcriptional regulator MvaT, GacA response regulator and histidine kinase. Amino acid substitutions were located in domain structures of these proteins. Practically all of these proteins have been described in the literature as being relevant to phenazines biosynthesis. GacA protein as a part of secondary metabolism GacS/GacA regulatory system is directly involved in biosynthesis of these metabolites [31]. Histidine kinases are the huge class of proteins that are the part of two-component signal systems which can regulate phenazines biosynthesis in the same way as GacS/GacA regulatory system [32]. MvaT is a negative controller of the biofilm formation [27]. Biofilm formation in turn increases the local concentration of bacterial cells, and as a consequence concentration of $\mathrm{N}$-acyl-homoserine lactone. $\mathrm{N}$ acyl-homoserine lactone is a signaling molecule that interacts with $p h z R$ gene and participates in regulation of phenazine production $[38,39]$. It is known that extracellular transport of several toxins and exoenzymes is conducted by the type I secretion system ATPase for but it is not yet reliably clear how phenazine antibiotics are allocated from the cells. Therefore it is potentially possible that type I secretion 
system is involved in the release of phenazines. Phenylalanine hydroxylase transcriptional activator PhhR is engaged in phenylalanine degradation and homeostasis [21,22]. Phenylalanine in turn is negative regulator of DAHP synthases engaged in catalysis of biochemical reactions that lead to phenazine formation [23]. Thus, mutations in these genes may potentially have an influence on phenazine synthesis and secretion in Pseudomonas bacteria.

According to the result of comparison of $P$. chlororaphis subsp. aurantiaca B-162/255 and $P$. chlororaphis subsp. aurantiaca B-162/17 genomes 19 mutations were detected. However, only 2 deletions and 5 SNPs (2 of them are reverse mutations) could probably induce changes in phenazine production. The detected reverse mutations took place in genes encoding phenylalanine hydroxylase transcriptional activator PhhR and type I secretion system of ATPase. Given the fact that the level of phenazine production by B-162/17 is somewhat reduced compared with the similar parameter of B-162/255 we can speculate about the impact of these two mutations on phenazine synthesis with greater confidence. As to the remaining mutations, their significance for phenazine production is difficult to evaluate as well as the reasons of phenazine synthesis on minimal media by B-162/17 strain.

\section{References}

1. Price-Whelan A, Dietrich LEP, Newman DK (2006) Rethinking "secondary" metabolism: physiological roles for phenazine antibiotics. Nature Chemical Biology 2(2):71-78

2. Pierson III LS, Pierson EA (2010) Metabolism and function of phenazines in bacteria: impacts on the behavior of bacteria in the environment and biotechnological processes. Appl Microbiol Biotech 86(6):1659-1670

3. Hernandez ME, Kappler A, Newman DK Hernandez ME (2004) Phenazines and other redox-active antibiotics promote microbial mineral reduction. Appl Environ Microbiol 70(2):921-928

4. Pauliukaite R, Ghica ME, Barsan MM, Brett CMA (2010) Phenazines and polyphenazines in electrochemical sensors and biosensors. Analytical Letters 43:1588-1608

5. Deppenmeier U (2004) The membrane-bound electron transport system of Methanosarcina J Bioenerg Biomembr 36:55-64

6. . Mavrodi DV, Blankenfeldt W, Thomashow LS, Mentel M 2006 Phenazine compounds in fluorescent Pseudomonas spp biosynthesis and regulation. Annual Review of Phytopathology 44:417-445

7. Dietrich LE, Price-Whelan A, Petersen A, Whiteley M, Newman DK (2006) The phenazine pyocyanin is a terminal signaling factor in the quorum sensing network of Pseudomonas aeruginosa. Molecular Microbiology 61:1308-1321

8. Schroder U (2007) Anodic electron transfer mechanisms in microbial fuel cells and their energy efficiency. Phys Chem Chem Phys 9:2619-2629

9. Feng J, Qian Y, Wang Z, Wang X, Xu S, Chen K, Ouyang P (2018) Enhancing the performance of Escherichia coli-inoculated microbial fuel cells by introduction of the phenazine-1-carboxylic acid pathway. J Biotechnol 275:1-6 
10. Sawhney SN, Boykin DW (1979) Phenazines with two cationic side chains as potential antimalarials. J Pharm S 68(4):524-526

11. Cimmino A, Evidente A, Mathieu V, Andolfi A, Lefranc F, Kornienkod A, Kiss R (2012) Phenazines and cancer. Nat Prod Rep. 29:487-501

12. Veremeenko EG, Lysak VV, Maksimova NP (2010) Obtaining and characteristic of Pseudomonas aurantiaca mutant strain, capable of phenazine antibiotics production on minimal media. Journal of the Belarusian State University Biology 2(2):47-53

13. Veremeenko EG, Maksimova NP (2010) Activation of the antioxidant complex in Pseudomonas aurantiaca - producer of phenazine antibiotics. Microbiology 79: 439-444

14. Haynes WC, Stodola FH, Locke JM, Pridham TG, Conway HF, Sohns VE, Jackson RW (1956) Pseudomonas aureofaciens Kluyver and phenazine a-cartboxylic acid, its characteristic pigment. Journal of bacteriology 72:412-417

15. Maniatis T, Fritsch EE, Sambrook J (1982) Molecular cloning: a laboratory mannual.1th edn. Cold Spring Harbour University, NY

16. Liaudanskaya Al, Veremeenko EG, Maksimova NP (2019) Analysis of Pseudomonas chlororaphis subsp. aurantiaca B162 bacterial genome. Microbial Biotechnology: Fundamental and Applied Aspects 11: 102-113

17. Lewin B (2012) Genes. $9^{\text {th }}$ Jones and Bartlett Publishers, MA

18. Brown NL, Stoyanov JV, Kidd SP, Hobman JL (2003) The MerR family of transcriptional regulators. FEMS Microbiology Reviews 27:145-163

19. Wachi M, Doi M, Okada Y, Matsuhashi M (1989) New mre genes mreC and mreD, responsible for formation of the rod shape of Escherichia coli J Bacteriology 171(12):6511-6516

20. Thatcher DR, Cain RB (1972) The kinetic properties of 3-carboxy-cis-cismuconate cycloisomerase. Proceedings of the Biochemical Society 127:33-34

21. Herrera MC, Duque E, Rodríguez-Herva JJ, Fernández-Escamilla AM, Ramos JL (2010) Identification and characterization of the PhhR regulon in Pseudomonas putida. Environ Microbiol 12(6):1427-1438

22. Song J, Jensen RA (1996) PhhR, a divergently transcribed activator of the phenylalanine hydroxylase gene cluster of Pseudomonas aeruginosa. Mol Microbiol 22(3):497-507

23. Light SH, Anderson WF (2013) The diversity of allosteric controls at the gateway to aromatic amino acid biosynthesis. The Protein Society 22(4):395-404

24. Shingler V (1996) Signal sensing by $\sigma^{54}$-dependent regulators: derepression as a control mechanism. Molecular Microbiology 19(3):409-416

25. Costa TR, Felisberto-Rodrigues C, Meir A, Prevost MS, Redzej A, Trokter M, Waksman G (2015) Secretion systems in Gram-negative bacteria: structural and mechanistic insights. Nat Rev Microbiol. https://doi.org/10.1038/nrmicro3456 
26. Green ER, Mecsas J (2016) Bacterial Secretion Systems: An Overview. Microbiology Spectrum. https://doi.org/10.1128/microbiolspec.vmbf-0012-2015

27. Vallet I, Diggle SP, Stacey RE, Ca'mara M, Ventre I, Lory S, Lazdunski A, Williams P, Filloux A (2004) Biofilm formation in Pseudomonas aeruginosa: fimbrial CUP gene clusters are controlled by the transcriptional regulator MvaT. J Bacteriology 186(9):2880-2890

28. Schiessl KT, Hu F, Jo J, Nazia SZ, Wang B, Price-Whelan A, Min W, Dietrich LEP (2019) Phenazine production promotes antibiotic tolerance and metabolic heterogeneity in Pseudomonas aeruginosa Nat Commun. https://doi.org/10.1038/s41467-019-08733-w

29. McMackin EAW, Marsden AE, Yahr TL (2019) H-NS Family members MvaT and MvaU regulate the Pseudomonas aeruginosa Type III secretion system. J Bacteriology.

https://doi.org/10.1128/jb.00054-19

30. Lehmann M, Tshisuaka B, Fetzner S, Lingens F (1995) Molecular cloning of the isoquinoline 1oxidoreductase genes from Pseudomonas diminuta 7, structural analysis of iorA and iorB, and sequence comparisons with other molybdenum-containing hydroxylases. J Biol Chem 270(24): $14420-14429$

31. Yan Q, Lopes LD, Shaffer BT, Kidarsa TA, Vining O, Philmus B, Song C, Stockwell VO, Raaijmakers JM, McPhail KL, Andreote FD, Chang JH, Lope JE (2018) Secondary Metabolism and Interspecific Competition Affect Accumulation of Spontaneous Mutants in the GacS-GacA Regulatory System in Pseudomonas protegens. MBio. https://doi.org/10.1128/mbio.01845-17

32. Chambonnierm G, Roux L, Redelberger D, Fadel F, Filloux A, Sivaneson M, de Bentzmann, Bordi C et al (2016) The hybrid histidine kinase lads forms a multicomponent signal transduction system with the gacs/gaca two-component system in Pseudomonas aeruginosa. PLOS Genetics.

https://doi.org/10.1371/journal.pgen.1006032

33. Arnérm ES, Holmgren A (2000) Physiological functions of thioredoxin and thioredoxin reductase. European Journal of Biochemistry 267(20):6102-6109

34. Cooper CE, Nicholls P, Freedman JA (1990) Cytochrome C oxidase: structure, function, and membrane topology of the polypeptide subunits 1. Biochem Cell Biol 69:586-607

35. Benz I, Schmidt MA (2011) Structures and functions of autotransporter proteins in microbial pathogens. International Journal of Medical Microbiology 301(6):461-468

36. BRENDA Web. https://www.brenda-enzymes.org/enzyme.php?ecno=2.3.1.109. Accessed 9 December 2020

37. Cabeen MT, Leiman SA, Losick R (2016) Colony-morphology screening uncovers a role for the Pseudomonas aeruginosa nitrogen-related phosphotransferase system in biofilm formation. Mol Microbiol 99(3): 557-570

38. Maddula VSRK, Zhang Z, Pierson EA, Pierson III LS (2006) Quorum sensing and phenazines are Involved in biofilm formation by Pseudomonas chlororaphis (aureofaciens) strain 30-84. Microbial Ecology 52, 289-301 
39. Khan SR, Herman J, Krank J, Serkova NJ, Churchill MEA, Suga H, Farrand SK (2007) N-(3-

hydroxyhexanoyl)-I-homoserine lactone is the biologically relevant quormone that regulates the phz operon of Pseudomonas chlororaphis strain 30-84. Appl Environ Microbiol 73(22): 7443-7455

\section{Figures}

$$
\begin{array}{cc}
\begin{array}{c}
\text { mutagenesis coupled with } \\
\text { selection to }
\end{array} & \begin{array}{c}
\text { mutagenesis coupled with } \\
\text { selection of phenazines } \\
\text { m-fluorophenylalanine }
\end{array} \\
\text { producers on minimal media }
\end{array}
$$

\begin{tabular}{|c|c|c|c|}
\hline Name & Start & p-value & Sites \\
\hline 1. 162 & 236 & $4.28 e-25$ & PLDAPLLIEG ETGTGKELLARAC LAS RGQS IMALNC AGLPESMAET \\
\hline 2. $162 / 255$ & 236 & $9.69 e-24$ & PLDAPLLIEG ETGTGKELLARAC LAS RGQS ILALNC AGLPESMAET \\
\hline 2. $162 / 255$ & 152 & $5.58 e-21$ & ANKSRINGLR VKVKGDVFLADIA LQSE DDSEAMA $G A V$ LTLHRADRVG \\
\hline 1. 162 & 152 & $5.58 e-21$ & ANKSRINGLR VKVKGDVFLADIA LQSE DDSEAMA $G A V$ LTLHRADRVG \\
\hline 2. $162 / 255$ & 61 & $2.59 e-19$ & LQFQALRPKF ESIA $G V F G V K R V G L M$ SERR MELNALLG ALEFPVLSID \\
\hline 1. 162 & 61 & $2.59 \mathrm{e}-19$ & LQFQALRPKF ESIA $G V F G V K R V G L M$ SERR MELNALL $G$ ALEFPVLSID \\
\hline 2. $162 / 255$ & 297 & $9.29 \mathrm{e}-19$ & ARAEGKLGLL ELTAGGTLFLDGVGEMS RLQVKLLRFLQ DGCFRRVGSD \\
\hline 1. 162 & 297 & $9.29 e-19$ & ARAEGKLGLL ELTAGGTLFLDGVGEMS RLQVKLLRFLQ DGCFRRVGSD \\
\hline 2. $162 / 255$ & 348 & $1.73 e-18$ & VYLDVRVICA TQVDLSELCARGEFRQDLY RLNVLSL I PPLRECLDGI \\
\hline 1. 162 & 348 & $1.73 e-18$ & VYLDVRVICA TQVDLSELCARGEFRQDLY RLNVLSL I PPLRECLDGL \\
\hline
\end{tabular}

\section{Figure 1}

\begin{tabular}{|c|c|c|c|c|}
\hline Name & Start & $p$-value & & Sites \\
\hline 2. $162 / 255$ & 81 & $1.60 \mathrm{e}-21$ & FIGLLEVVRS & FIVIRI $G S Q L E R R F N L R V Y Q$ AAFERNLFRG \\
\hline 1. 162 & 81 & $1.60 \mathrm{e}-21$ & FIGLLEVVRS & FIVIRI $G$ SQLERRFNLRVYQ AAFERNLFRG \\
\hline 2. $162 / 255$ & 339 & $8.29 \mathrm{e}-20$ & QVSFEQVSAG & PPGKRMATLQQVSFNL $G$ ZRF VLGVLGASGS \\
\hline 1. 162 & 339 & $1.95 \mathrm{e}-19$ & QVSFEQVSAG & PPGRMATLQQVSFNL $G$ A \\
\hline
\end{tabular}

Stages of parent strain P. chlororaphis subsp. aurantiaca B-162 mutagenesis

\section{Figure 2}

Motifs with substitution in phenylalanine hydroxylase transcriptional activator PhhR Note: substitution is highlighted with a border

Figure 3

Motifs with substitution in Type I secretion system ATPase Note: substitution is highlighted with a border 


\begin{tabular}{|c|c|c|c|c|}
\hline Name & Start & $p$-value & & Sites \\
\hline 2. $162 / 255$ & 74 & $9.51 \mathrm{e}-40$ & KSALPLSGAP & TGELIETK DN RGLKAWKEQYGAAT VDSWLRS \\
\hline 1. 162 & 74 & $2.75 e-39$ & KSALPLSGAP & KTRRARVVKVYQN TGELIETK@GN RGLKAWKEQYGAAT VDSWLRS \\
\hline 2. $162 / 255$ & 25 & $3.41 e-38$ & QEQLAQLESL & KNDA LKKEIEFEEKLQ LMKTYGKSLRDIIAILD HIP GS ALPLSGAPKT \\
\hline 1. 162 & 25 & $3.41 \mathrm{e}-38$ & QEQLAQLESL & KNDA $A K K E I E F E E K L Q$ LMKTYGKSLRDIIAILD HP GS ALPLSGAPKT \\
\hline
\end{tabular}

\section{Figure 4}

Motifs with substitution in transcriptional regulator MvaT Note: substitution is highlighted with a border

\section{Name}

2. $162 / 255$

1. 162

1. 162

2. $162 / 255$

2. $162 / 255$

1. 162

2. $162 / 255$

1. 162
Start $p$-value

$154 \quad 4.79 \mathrm{e}-23$

$154 \quad 4.79 \mathrm{e}-23$

104

104

25

25

58

58

\section{$1.13 \mathrm{e}-22$}

5.01e-22

$6.82 \mathrm{e}-21$

$6.82 \mathrm{e}-21$

$5.72 \mathrm{e}-20$

$5.72 \mathrm{e}-20$
Sites

CQKVQIISDK LCLS KTVNTYRYRIFEKLSISSDVELTL LAVRHGMVDA CQKVQIISDK LCLS KTVNTYRYRIFEKLSISSDVELTL LAVRHGMVDA QAIRLVFAGQ RYIS QIAQQLVFKSFQ SSES FDALSE REIQIALMIV QAIRLVFAGQ RYIR QIAQQLVFKSFQ SSES FDALSE REIQIAIMIV ESGEESLIKA RELK DVVLMDVKM GIGGLEATRKLLRS HPDIKVVAVT ESGEESLIKA RELK DVVLMDVKM GIGGLEATRKLLRS HPDIKVVAVT RKLLRSHPDI KVVAVTVCEED F TRLLQA $G A A G Y L T G$ AGLNEMVQAI RKLIRSHPDI KVVAVTVCEED F TRLLQA $G A A G Y L T K G$ AGLNEMVQAI

\section{Figure 5}

Motifs with substitution in GacA response regulator Note: substitution is highlighted with a border

\section{Name}

2. $162 / 255$

1. 162

1. 162

2. $162 / 255$

\section{Start}

100

100

171

171 p-value

\section{Figure 6}

Motifs with substitution in histidine kinase Note: substitution is highlighted with a border 